\title{
Dietary patterns and abnormal glucose tolerance among Japanese: findings from the National Health and Nutrition Survey, 2012
}

\author{
Emiko Okada ${ }^{1}$, Kunihiko Takahashi ${ }^{2}$, Koshi Nakamura ${ }^{3}$, Shigekazu Ukawa ${ }^{3,4}$, \\ Saeka Takabayashi ${ }^{3}$, Mieko Nakamura ${ }^{5}$, Satoshi Sasaki ${ }^{6}$, Akiko Tamakoshi $^{3}$ and \\ Hidemi Takimoto ${ }^{1, *}$ \\ 'Department of Nutritional Epidemiology and Shokuiku, National Institute of Health and Nutrition, 1-23-1 Toyama, \\ Shinjuku-ku, Tokyo 162-8636, Japan: ${ }^{2}$ Department of Biostatistics, Nagoya University Graduate School of Medicine, \\ Nagoya, Japan: ${ }^{3}$ Department of Public Health, Hokkaido University Faculty of Medicine, Sapporo, Japan: ${ }^{4}$ Research \\ Unit of Advanced Interdisciplinary Care Science, Graduate School of Human Life Science, Osaka City University, \\ Osaka, Japan: ${ }^{5}$ Department of Community Health and Preventive Medicine, Hamamatsu University School of \\ Medicine, Hamamatsu, Japan: ${ }^{6}$ Department of Social and Preventive Epidemiology, School of Public Health, \\ Graduate School of Medicine, The University of Tokyo, Tokyo, Japan
}

Submitted 16 May 2018: Final revision received 12 November 2018: Accepted 20 December 2018: First published online 6 March 2019

\begin{abstract}
Objective: Previous studies have associated dietary patterns with diabetes risk in Western countries, but such studies among the Japanese population are scarce. The present study aimed to investigate dietary patterns associated with abnormal glucose tolerance determined by elevated glycated Hb (HbA1c) levels.

Design: The 2012 National Health and Nutrition Survey (NHNS) database was used for the cross-sectional study. Dietary patterns were analysed by factor analysis of twenty-five food items from the dietary intake survey and householdbased semi-weighed dietary records. OR and 95\% CI for elevated HbA1c levels $(\geq 6.5 \%)$ according to dietary patterns were estimated using logistic regression models.

Setting: Japan.

Participants: The study population comprised 9550 Japanese aged $\geq 40$ years registered in the nationwide NHNS.

Results: Three dietary patterns were identified: (i) high-bread and low-rice; (ii) high-meat and low-fish; and (iii) vegetable. The high-bread and low-rice pattern, characterised by high frequent consumption of bread, milk and dairy products, and fruits, and low rice intake, was associated with marginally decreased prevalence of elevated HbA1c levels $\left(P_{\text {trend }}=0 \cdot 047\right)$. The vegetable pattern, characterised by vegetables, mushrooms, soyabeans and soybean products, was significantly inversely associated with elevated HbA1c levels (4th $v$. 1st quartile: multivariable $\mathrm{OR}=0.68 ; 95 \%$ CI $0.49,0.95 ; P_{\text {trend }}=0.007$ ).

Conclusions: Our findings suggest that the vegetable pattern is associated with decreased prevalence of elevated HbA1c levels among Japanese.
\end{abstract}

\author{
Keywords \\ Dietary patterns \\ Factor analysis \\ HbAlc \\ Japanese \\ National Health and Nutrition Survey
}

An estimated 1.6 million deaths were directly caused by diabetes in $2015^{(1)}$ and in terms of the number of deaths worldwide, it is estimated that diabetes will be ranked seventh by $2030^{(2)}$. In Japan, the number of patients with diabetes is estimated to be 3166000 according to the 2014 Patient Survey ${ }^{(3)}$. The age-standardised prevalence of diabetes has remained constant at approximately $8 \%$ between 2003 and 2012 in Japan, with men and people aged $\geq 65$ years being most affected $^{(4)}$. A healthy diet, regular physical activity, maintaining normal body weight and avoiding tobacco use are effective in preventing the onset of type 2 diabetes ${ }^{(1)}$. Regarding the effect of dietary habit on diabetes, assessment of the overall dietary intake is required because diets involve multiple nutrients and food groups.

Recently, the association between healthy diet and diabetes risk has been investigated in Western and Asian countries. Results from previous studies suggest that the 
Mediterranean diet, the Dietary Approaches to Stop Hypertension (DASH) diet and diets with high Alternate Healthy Eating Index (AHEI) scores have the potential for preventing type 2 diabetes in general populations ${ }^{(5-9)}$. In previous meta-analyses, a posterioridefined dietary patterns identified as healthy/prudent were associated with a reduced risk of developing type 2 diabetes and those identified as unhealthy/Western patterns were associated with an increased risk $^{(10-13)}$. The Japanese diet consists of a wide variety of foods ${ }^{(14)}$ and is different from diets in Western countries, being characterised by high intakes of soya products, mushrooms and seaweeds. In Japan, it has been reported that a dietary pattern featuring frequent intake of white rice may impair glucose metabolism ${ }^{(15)}$ and a high-dairy, high-fruit-and-vegetable, low-alcohol pattern may be associated with a decreased risk of developing abnormal glucose tolerance ${ }^{(16)}$. On the other hand, another prospective study showed that dietary patterns were not associated with type 2 diabetes risk in Japanese individuals ${ }^{(17)}$. These previous results were inconsistent, partly due to the different methods applied to identify glucose tolerance abnormalities and the dietary methods used in developing dietary patterns. The methods used to assess diabetes in epidemiological studies include blood glucose levels (fasting; 75-g oral glucose tolerance test; casual), glycated $\mathrm{Hb}$ (HbA1c) levels and selfreporting of physician-diagnosed diabetes. Therefore, the association between dietary patterns and abnormal glucose tolerance reflecting dietary intake among the Japanese population remains unknown.

In the present study, we aimed to explore the association between dietary patterns and glucose tolerance abnormality identified by HbA1c levels among Japanese adults using nationwide data from the 2012 National Health and Nutrition Survey (NHNS).

\section{Methods}

\section{Data source: the National Health and Nutrition}

\section{Survey}

The NHNS is a cross-sectional survey conducted by the Ministry of Health, Labour and Welfare in Japan every November since 1947. Details of the survey design have been described elsewhere ${ }^{(18)}$. Briefly, in 2012, the NHNS used a stratified single-stage cluster sample design across forty-seven prefectures. Census enumeration areas were drawn from each prefecture and residents aged $\geq 1$ year in all households from 475 selected census enumeration areas were eligible for participation in the survey. The NHNS is composed of three surveys: the dietary intake survey (a self-administered questionnaire including questions on the household population, meal patterns, daily step counts and dietary records); the lifestyle survey (a self-administered questionnaire including questions on smoking status, alcohol intake and sleep time); and a physical examination (measurement of height, weight, abdominal circumference and blood pressure; blood tests; and a medical interview). The 2012 survey sampled 24555 households and 12750 households responded (response rate: $51.9 \%)^{(18)}$. Based on official application procedures under Article 33 of the Statistics Act, we obtained approval from the Ministry of Health, Labour and Welfare, Japan and used individual-level data from the NHNS for the present study. In accordance with the Ethical Guidelines of Epidemiological Research ${ }^{(19)}$, our study was exempt from the application of these guidelines because we used anonymised data only.

\section{Dietary assessment}

The dietary intake survey, which used semi-weighed household dietary records to assess dietary intake, was conducted on a single day between 25 October and 7 December, excluding Sundays and public holidays. Trained interviewers visited each household to explain the method of generating dietary records before the survey. Dietary records were weighed by taking an inventory of all foods, beverages, food waste, leftovers and foods eaten away from home that were consumed in the household. For shared dishes within the household, approximate proportions of each food were assigned to individual household members to estimate individual food intakes. Interviewers checked for any missing information and errors during household visits to collect the dietary records.

Nutrient intakes were calculated based on the Standard Tables of Food Composition in Japan, 2010, which were updated from the fifth revised and enlarged edition published in 2005. Foods were classified into seventeen large food groups (e.g. cereals; vegetables; fish and shellfish; etc.), thirty-three medium groups (e.g. rice and rice products; wheat flour and wheat products; green and yellow vegetables; other vegetables; raw fish and shellfish; seafood and processed products; etc.) and ninety-eight small groups (e.g. rice; bread; tomatoes; carrots; horse mackerels and sardines; salmon and trout; etc.) based on the food group tables in the $\mathrm{NHNS}^{(20)}$. The details of the food groups have been previously reported ${ }^{(21)}$.

\section{HbA1c measurement}

HbA1c concentration was measured using the latex agglutination nephelometry method (measuring instrument: BM9030) on non-fasting blood samples. Glucose tolerance abnormality was defined as elevated HbA1c concentration $\geq 6.5 \%$ determined by the National Glycohaemoglobin Standardization Program, based on the diabetes mellitus diagnostic criteria of the Japan Diabetes Society ${ }^{(22)}$. The Japan Diabetes Society defines diabetic type cases as having HbA1c level of $6.5 \%$ or above. 


\section{Study participants}

Out of 36408 participants from 12750 households in the 2012 survey, the following were excluded: 12888 participants aged $<40$ years, 11812 participants whose HbA1c levels were not measured in blood tests, and eight pregnant women or breast-feeding women. Furthermore, 1801 participants who answered in the affirmative to 'have been previously diagnosed as having diabetes' in the medical interview and thirty-nine participants who were being treated for diabetes at the time of the survey, using either insulin or oral drugs, were excluded because they were likely to have different dietary patterns by dietary instruction. The following were also excluded: participants with incomplete data on the dietary intake survey ( $n$ 179) and those with extremely low or high reported total energy intake, defined as consuming less than $50 \%$ or more than $150 \%$ of the estimated energy requirement for physical activity levels by age and sex based on the Dietary Reference Intakes for Japanese $(2015)^{(23)}$ ( $n$ 131). Finally, a total of 9550 participants aged $\geq 40$ years were included in the present analysis. We analysed the results of the present study using the NHNS as a simple random sample.

\section{Statistical analysis}

First, dietary patterns based on energy-adjusted intake using the residual method for food items were analysed by factor analysis using a varimax rotation. In the present study, most food items used for factor analysis belonged to the medium food groups based on the food group tables in the NHNS (e.g. rice and rice products; wheat flour and wheat products; green and yellow vegetables; other vegetables; raw fish and shellfish; seafood and processed products), excluding seasonings and spices. Wheat flour/ wheat flour products, fats/oils and beverages were reconstituted from five items of the small group, into three items. Variables based on these data with a $\mathrm{CV} \leq 0.3$ were excluded because these variables had approximately the same intake values among almost all participants and therefore contributed little to the factor analysis ${ }^{(24)}$. Finally, twenty-five food items were included in subsequent factor analysis: (i) rice and rice products; (ii) wheat flour; (iii) bread and Japanese buns; (iv) noodles (Japanese and Chinese noodles, buckwheat and buckwheat products, macaroni and spaghetti); (v) potatoes and potato products; (vi) sugars and sweeteners; (vii) soyabeans and soyabean products; (viii) green and yellow vegetables; (ix) other vegetables; (x) pickles; (xi) fruits; (xii) mushrooms; (xiii) algae; (xiv) raw fish and shellfish; (xv) seafood and processed seafood products; (xvi) animal meats and poultries; (xvii) eggs; (xviii) milk and dairy products; (xix) butter and margarine; (xx) vegetable fats and oils; (xxi) confectioneries; (xxii) alcoholic beverages; (xxiii) teas; (xxiv) coffee and cocoa; and (xxv) other beverages. To determine the number of factors to be retained, we considered components with an eigenvalue $>1 \cdot 0$, as well as the scree test results and interpretability of the factors. Factor scores were calculated for each participant, standardised to a mean value of 0 and an SD of 1 , and each participant was assigned a factor score for every identified pattern.

Second, participants were divided into quartiles based on factor scores for dietary patterns. Third, the associations of dietary pattern scores with participant characteristics and food and nutrient intakes were assessed by using simple linear regression analysis for continuous variables and the $\chi^{2}$ test for categorical variables. Finally, a sex- and age-adjusted model and multivariate model logistic regression analyses were performed to evaluate associations between dietary patterns and elevated $\mathrm{HbA} 1 \mathrm{c}$ levels $(\geq 6.5 \%)$. OR for elevated HbA1c levels were evaluated with dietary pattern scores in the second through fourth quartiles and compared with those in the first quartile. To examine the linear relationship, $P_{\text {trend }}$ values were obtained using the quartile factor scores for the dietary patterns as ordinal variables. The following variables were included in the multivariate models based on a review of the previous literature: sex, age (continuous variable), BMI $\left(<18.5,18.5-24.9\right.$ or $\left.\geq 25.0 \mathrm{~kg} / \mathrm{m}^{2}\right)$, smoking status (never, former, current smoker or unknown) and exercise habit (yes, no or unknown). Alcohol consumption status was not included in the multivariate models because alcohol intake was included in the factor analysis for dietary patterns. There were no significant interactions of sex between dietary patterns and elevated HbA1c levels. All statistical analyses were performed using the statistical software package SAS for Windows version 9.4. Differences were considered statistically significant at $P<0.05$.

\section{Results}

From the result of factor analysis, three dietary patterns were identified in the present study (the factor loading matrix for the three dietary patterns is presented in the online supplementary material, Supplemental Table 1). The first pattern had higher factor loadings of bread, milk and dairy products, and fruits, and lower factor loading of rice. The second pattern had higher factor loading of meat, and lower factor loadings of rice and fish. The third pattern had higher factor loadings of vegetables, mushrooms, soyabeans and soyabean products. These dietary patterns were labelled as follows: (i) high-bread and low-rice; (ii) high-meat and low-fish; and (iii) vegetable.

Participant characteristics for the three dietary patterns by factor score quartiles are shown in Table 1. Participants in the highest quartiles for the high-bread and low-rice pattern and vegetable pattern were older, more likely to be women, more likely to report exercise habits, and less likely to be current smokers and current drinkers, compared with those in the lowest factor score quartiles. Participants in the highest quartile for the high-meat and low-fish pattern 
Table 1 Characteristics of participants according to factor score quartiles for the three dietary patterns found among Japanese adults ( $n$ 9550) aged $\geq 40$ years, 2012 National Health and Nutrition Survey

\begin{tabular}{|c|c|c|c|c|c|c|c|c|c|c|c|c|}
\hline & \multicolumn{4}{|c|}{ High-bread and low-rice } & \multicolumn{4}{|c|}{ High-meat and low-fish } & \multicolumn{4}{|c|}{ Vegetable } \\
\hline & \multicolumn{2}{|c|}{ Quartile 1 (low) } & \multicolumn{2}{|c|}{ Quartile 4 (high)* } & \multicolumn{2}{|c|}{ Quartile 1 (low) } & \multicolumn{2}{|c|}{ Quartile 4 (high)* } & \multicolumn{2}{|c|}{ Quartile 1 (low) } & \multicolumn{2}{|c|}{ 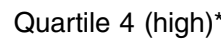 } \\
\hline & Mean or $\%$ & SD & Mean or $\%$ & SD & Mean or $\%$ & SD & Mean or $\%$ & SD & Mean or $\%$ & SD & Mean or $\%$ & SD \\
\hline Age (years) & $60 \cdot 2$ & $12 \cdot 6$ & $64 \cdot 7$ & $11 \cdot 1$ & $68 \cdot 3$ & 11.2 & $57 \cdot 3$ & $11 \cdot 1$ & 59.9 & $12 \cdot 4$ & $65 \cdot 4$ & $10 \cdot 8$ \\
\hline Women (\%) & $40 \cdot 1$ & - & 73.1 & - & $55 \cdot 2$ & - & 61.4 & - & $46 \cdot 4$ & - & 67.4 & - \\
\hline Current smoker (\%) & $24 \cdot 3$ & - & $9 \cdot 8$ & - & 11.5 & - & 19.9 & - & $25 \cdot 9$ & - & 7.9 & - \\
\hline Current drinker (\%) & $61 \cdot 8$ & - & $36 \cdot 2$ & - & $43 \cdot 2$ & - & $52 \cdot 6$ & - & $58 \cdot 4$ & - & $39 \cdot 3$ & - \\
\hline Exercise habits, yes (\%) & 24.7 & - & $37 \cdot 1$ & - & 30.7 & - & $29.2 \dagger$ & - & $27 \cdot 0$ & - & $36 \cdot 3$ & - \\
\hline BMI $\left(\mathrm{kg} / \mathrm{m}^{2}\right)$ & 23.5 & 3.4 & $22 \cdot 7$ & $3 \cdot 2$ & $23 \cdot 2$ & 3.3 & 22.7 & 3.2 & 23.1 & 3.4 & $23 \cdot 2$ & $3 \cdot 3$ \\
\hline $\begin{array}{l}\text { Systolic blood pressure } \\
\text { (mmHg) }\end{array}$ & 136 & $18 \cdot 2$ & 133 & $18 \cdot 0$ & 137 & $17 \cdot 7$ & 133 & $18 \cdot 0$ & 134 & $18 \cdot 8$ & 134 & $17 \cdot 3$ \\
\hline $\begin{array}{l}\text { Diastolic blood pressure } \\
\quad(\mathrm{mmHg})\end{array}$ & $81 \cdot 9$ & $11 \cdot 1$ & $79 \cdot 7$ & $10 \cdot 5$ & $80 \cdot 0$ & $10 \cdot 8$ & $79 \cdot 7$ & $10 \cdot 5$ & $81 \cdot 3$ & $11 \cdot 3$ & $79 \cdot 7$ & $10 \cdot 4$ \\
\hline Total cholesterol (mg/dl) & 200 & $34 \cdot 6$ & 209 & $35 \cdot 3$ & 198 & 34.0 & 209 & $35 \cdot 3$ & 203 & $35 \cdot 7$ & 204 & $34 \cdot 3$ \\
\hline HDL-cholesterol (mg/dl) & $59 \cdot 0$ & $16 \cdot 2$ & $62 \cdot 2$ & $15 \cdot 8$ & $57 \cdot 7$ & $15 \cdot 3$ & $62 \cdot 2$ & $15 \cdot 8$ & $60 \cdot 3$ & $16 \cdot 3$ & $60 \cdot 3$ & $16 \cdot 0$ \\
\hline LDL-cholesterol (mg/dl) & 116 & $30 \cdot 8$ & 122 & $30 \cdot 8$ & 114 & $29 \cdot 7$ & 122 & $30 \cdot 8$ & 118 & 31.4 & 118 & $29 \cdot 6$ \\
\hline
\end{tabular}

*Simple linear regression analysis and the $x^{2}$ test were used for continuous and categorical variables, respectively. $P$ were all $<0.001$, with one exception. $\dagger P=0.074$.

were younger, more likely to be women, and more likely to be current smokers and current drinkers.

Table 2 shows food intakes for the three dietary patterns by factor score quartile. The highest quartile for the highbread and low-rice pattern had higher intakes of bread, green and yellow vegetables, fruits, milk and dairy products, butter and margarine, confectioneries, and coffee and cocoa, and lower intakes of rice, meat, eggs and alcoholic beverages, compared with the lowest quartile for factor score. The highest quartile for the high-meat and low-fish pattern had higher intakes of meat, bread, noodles, alcoholic beverages, and coffee and cocoa, and lower intakes of fish, rice, pickles, fruits, algae and tea. The highest quartile for the vegetable pattern had higher intakes of vegetables, potatoes, soyabeans and soyabean products, fruits, mushrooms, algae and tea, and lower intakes of bread, alcoholic beverages, and coffee and cocoa.

Table 3 shows the nutrient intakes for the three dietary patterns by factor score quartile. The highest quartiles for the high-bread and low-rice, and vegetable patterns had higher intakes of nutrients such as protein, fats, minerals, vitamins and dietary fibre, but not some nutrients. The highest quartile for the high-meat and low-fish pattern had lower intakes of most nutrients, except for total fat and fatty acids, compared with the lowest quartile.

The results of multivariate logistic regression analysis models for OR of elevated HbA1c levels ( $\geq 6.5 \%)$ according to the three dietary patterns by factor score quartiles are shown in Table 4. There were 309 participants with $\mathrm{HbA} 1 \mathrm{c} \geq 6.5 \%$. The high-bread and low-rice pattern was marginally inversely associated with the prevalence of elevated HbA1c levels $\left(P_{\text {trend }}=0 \cdot 047\right)$. For the vegetable pattern, higher factor score quartiles were associated with decreased prevalence of elevated HbA1c levels, with multivariate OR of 0.94 (95\% CI 0.69, 1.28), 0.70 (95\% CI $0.50,0.98)$ and 0.68 (95\% CI $0.49,0.95)$ for quartiles 2 to 4 , respectively, compared with quartile 1 $\left(P_{\text {trend }}=0.007\right)$. No significant association between the high-meat and low-fish pattern and elevated HbA1c levels was observed.

\section{Discussion}

We identified three major dietary patterns in a general Japanese population aged $\geq 40$ years from the nationwide NHNS: high-bread and low-rice; high-meat and low-fish; and vegetable. The vegetable pattern, characterised by higher frequent consumption of vegetables, mushrooms, soyabeans and soyabean products, was associated with decreased prevalence of elevated HbA1c levels. The highbread and low-rice pattern, characterised by higher frequent consumption of bread, milk and dairy products, and fruits, and low rice, showed a marginally inverse association with elevated HbA1c levels.

The inverse association for the vegetable pattern is consistent with the literature, including Western studies, that showed a linear relationship of reduced risk of diabetes among participants with healthy or prudent dietary patterns, characterised by high intakes of mainly vegetables, legumes and fruits ${ }^{(25-27)}$. However, some studies in Japan have also shown no association between so-called healthy dietary patterns and glucose metabolism ${ }^{(15-17)}$. Our study methods differ from those used in previous studies in Japan which based dietary assessment on the FFQ and included one prospective study. Although the NHNS is a survey based on a single day, consumption of vegetables, fruits, mushrooms, soyabeans and algae is generally habitual. These recorded food consumptions were reflected in dietary patterns; therefore, it is possible that the vegetable pattern was associated with a decline in elevated HbA1c levels. In addition, previous studies 
Table 2 Food intakes according to factor score quartiles for the three dietary patterns found among Japanese adults ( $n$ 9550) aged $\geq 40$ years, 2012 National Health and Nutrition Survey

\begin{tabular}{|c|c|c|c|c|c|c|c|c|c|c|c|c|}
\hline & \multicolumn{4}{|c|}{ High-bread and low-rice } & \multicolumn{4}{|c|}{ High-meat and low-fish } & \multicolumn{4}{|c|}{ Vegetable } \\
\hline & \multicolumn{2}{|c|}{$\begin{array}{l}\text { Quartile } 1 \\
\text { (low) }\end{array}$} & \multicolumn{2}{|c|}{$\begin{array}{c}\text { Quartile } 4 \\
\text { (high) }^{\star}\end{array}$} & \multicolumn{2}{|c|}{$\begin{array}{l}\text { Quartile } 1 \\
\text { (low) }\end{array}$} & \multicolumn{2}{|c|}{$\begin{array}{c}\text { Quartile } 4 \\
\text { (high) }^{\star}\end{array}$} & \multicolumn{2}{|c|}{$\begin{array}{l}\text { Quartile } 1 \\
\text { (low) }\end{array}$} & \multicolumn{2}{|c|}{$\begin{array}{l}\text { Quartile } 4 \\
\text { (high)* }^{*}\end{array}$} \\
\hline & Mean & SD & Mean & SD & Mean & SD & Mean & SD & Mean & SD & Mean & SD \\
\hline Rice and rice products $(\mathrm{g})$ & 481 & 187 & 239 & 130 & 461 & 181 & 251 & 155 & 374 & 201 & 329 & 168 \\
\hline Wheat flour (g) & 4.25 & $15 \cdot 0$ & 3.01 & 11.9 & 1.28 & 4.7 & $6 \cdot 89$ & $20 \cdot 1$ & 3.69 & $12 \cdot 9$ & 3.51 & 14.4 \\
\hline Breads and Japanese bun (g) & 6.53 & $20 \cdot 8$ & $70 \cdot 5$ & 54.8 & 14.9 & $32 \cdot 1$ & $58 \cdot 2$ & 54.6 & 53.0 & $57 \cdot 0$ & $23 \cdot 0$ & $36 \cdot 8$ \\
\hline Noodles $(\mathrm{g})$ & $52 \cdot 3$ & 91.3 & $65 \cdot 2$ & $96 \cdot 3$ & $25 \cdot 6$ & 61.4 & 102 & 121 & $67 \cdot 2$ & 102 & $57 \cdot 6$ & 94.9 \\
\hline Potatoes and potato products $(\mathrm{g})$ & $60 \cdot 1$ & 73.4 & 57.4 & $70 \cdot 7$ & $72 \cdot 9$ & 83.6 & 49.9 & $68 \cdot 1$ & 37.4 & $50 \cdot 9$ & $85 \cdot 8$ & 93.9 \\
\hline Sugars and sweeteners $(\mathrm{g})$ & 5.04 & $6 \cdot 00$ & 11.0 & $12 \cdot 3$ & 8.36 & $9 \cdot 81$ & 7.01 & 8.47 & $7 \cdot 90$ & $10 \cdot 2$ & 7.96 & 9.07 \\
\hline Soyabeans and soyabean products (g) & 63.8 & $73 \cdot 8$ & $72 \cdot 1$ & $85 \cdot 0$ & $80 \cdot 0$ & 84.9 & $54 \cdot 0$ & $72 \cdot 5$ & 38.8 & 51.9 & 103 & $97 \cdot 0$ \\
\hline Green and yellow vegetables $(\mathrm{g})$ & $79 \cdot 4$ & $73 \cdot 4$ & 122 & 104 & 109 & 98.8 & $89 \cdot 4$ & $84 \cdot 1$ & 53.0 & 53.8 & 160 & 112 \\
\hline Other vegetables $(\mathrm{g})$ & 199 & 133 & 176 & 120 & 173 & 125 & 209 & 136 & 105 & 77 & 292 & 145 \\
\hline Pickles (g) & $17 \cdot 5$ & 33.6 & $13 \cdot 8$ & $27 \cdot 4$ & 28.5 & $42 \cdot 5$ & $6 \cdot 46$ & 14.5 & 13.7 & $25 \cdot 2$ & $16 \cdot 5$ & $32 \cdot 4$ \\
\hline Fruits $(\mathrm{g})$ & $46 \cdot 9$ & 73.8 & 228 & 175 & 168 & 169 & $97 \cdot 2$ & 118 & $75 \cdot 6$ & 104 & 192 & 170 \\
\hline Mushrooms (g) & $20 \cdot 0$ & $34 \cdot 0$ & $18 \cdot 8$ & $29 \cdot 4$ & $15 \cdot 9$ & $24 \cdot 6$ & $23 \cdot 2$ & $36 \cdot 2$ & 6.47 & $12 \cdot 7$ & $40 \cdot 3$ & $45 \cdot 8$ \\
\hline Algae $(\mathrm{g})$ & $10 \cdot 2$ & $20 \cdot 3$ & $14 \cdot 0$ & $25 \cdot 8$ & $16 \cdot 7$ & 31.3 & $7 \cdot 81$ & $16 \cdot \overline{4}$ & $8 \cdot 78$ & $17 \cdot 4$ & $15 \cdot 6$ & 30.5 \\
\hline Raw fish and shellfish $(\mathrm{g})$ & 44.4 & $61 \cdot 1$ & $63 \cdot 1$ & $72 \cdot 5$ & $84 \cdot 1$ & $86 \cdot 5$ & $31 \cdot 0$ & $46 \cdot 7$ & 71.3 & 81.5 & $41 \cdot 8$ & $57 \cdot 6$ \\
\hline Seafood and processed products $(\mathrm{g})$ & 33.7 & $47 \cdot 1$ & 31.7 & 44.2 & $50 \cdot 6$ & $55 \cdot 6$ & $19 \cdot 0$ & 31.7 & 29.9 & 44.6 & 37.4 & $46 \cdot 1$ \\
\hline Animal meats and poultry $(\mathrm{g})$ & 101 & $75 \cdot 8$ & $51 \cdot 8$ & 49.7 & $34 \cdot 1$ & $36 \cdot 9$ & 121 & $75 \cdot 2$ & $56 \cdot 8$ & $56 \cdot 3$ & $90 \cdot 6$ & $70 \cdot 3$ \\
\hline Eggs $(g)$ & $42 \cdot 3$ & $37 \cdot 2$ & 29.5 & $30 \cdot 0$ & 33.9 & 33.6 & 34.6 & 34.5 & $36 \cdot 6$ & $35 \cdot 8$ & $34 \cdot 2$ & $32 \cdot 9$ \\
\hline Milk and dairy products $(\mathrm{g})$ & 33.6 & $66 \cdot 7$ & 203 & 156 & 112 & 139 & 103 & 125 & 88.8 & 127 & 127 & 137 \\
\hline Butter and margarine $(\mathrm{g})$ & 0.38 & 1.57 & $4 \cdot 14$ & 6.07 & 0.43 & 1.68 & 4.07 & 6.09 & $3 \cdot 36$ & 5.72 & 0.95 & 2.56 \\
\hline Vegetable fats and oils (g) & $10 \cdot 3$ & $9 \cdot 11$ & $5 \cdot 23$ & 5.69 & $4 \cdot 11$ & 4.89 & 11.4 & 9.80 & 6.93 & $7 \cdot 14$ & 7.73 & 8.22 \\
\hline Confectioneries (g) & 8.92 & 21.5 & 43.9 & $55 \cdot 1$ & 27.9 & 44.5 & 24.4 & 41.7 & 31.0 & 50.7 & $21 \cdot 2$ & 35.5 \\
\hline Alcoholic beverages (g) & 235 & 383 & $55 \cdot 0$ & 147 & 102 & 227 & 160 & 327 & 237 & 383 & 64.4 & 172 \\
\hline Tea $(\mathrm{g})$ & 304 & 350 & 382 & 392 & 511 & 456 & 222 & 272 & 252 & 317 & 428 & 425 \\
\hline Coffee and cocoa $(\mathrm{g})$ & 125 & 183 & 211 & 219 & $93 \cdot 1$ & 145 & 257 & 236 & 233 & 240 & 127 & 168 \\
\hline Other beverages (g) & $86 \cdot 7$ & 205 & $92 \cdot 0$ & 208 & $56 \cdot 5$ & 162 & 115 & 234 & 119 & 249 & $66 \cdot 6$ & 174 \\
\hline
\end{tabular}

${ }^{\star} P_{\text {trend }}$ used in the general linear model were all $<0.001$.

applied different methods to identify glucose tolerance abnormalities: HbA1c, 75-g oral glucose tolerance test and self-reported physician-diagnosed diabetes ${ }^{(15-17)}$. Because HbA1c is not influenced by dietary conditions and daily values are relatively stable, it is a useful objective indicator of glucose metabolism for epidemiological studies. A possible mechanism for the protective effect of vegetable patterns on diabetes may be due to the content of vegetables, fruits, mushrooms and soyabeans, which are rich in antioxidants, fibres, carotenoids, $\mathrm{Mg}$ and folic acid ${ }^{(28)}$. The vegetable pattern may reduce elevated HbA1c levels as a result of the beneficial effect of combined higher habitual consumption of foods such as vegetables, fruits, mushrooms and soyabeans.

The findings for the high-bread and low-rice pattern indicated that elevated HbA1c levels tend to be marginally higher among participants with lower factor score on the high-bread and low-rice pattern. A previous study in Japan showed that a dietary pattern characterised by frequent consumption of bread and infrequent consumption of white rice was associated with decreased HbA1c concentrations $^{(15)}$. A meta-analysis of four prospective studies (including seven data points) indicated that higher consumption of white rice is associated with an increased risk of type 2 diabetes, particularly among Asian populations $^{(29)}$. The Asian population is known to consume more white rice than the Western population. White rice has a high glycaemic index, which is a value assigned to foods indicating the degree of increase in blood glucose levels following their ingestion ${ }^{(30)}$. In addition, white rice is low in insoluble dietary fibres, total minerals, lignans, phytooestrogens, phenolic compounds and phytic acid due to the refining process ${ }^{(31)}$, and these nutrients have a potentially protective role in diabetes risk. Because our study identified the dietary patterns using dietary records from a single day, the association between the high-bread and low-rice pattern and HbA1c may not have been clearly observed although a marginal trend was identified. In Japan, the intake of staple foods such as rice or bread generically differs according to the day, so the current dietary pattern may not reflect habitual intakes of staple foods. Furthermore, the high-bread and low-rice pattern had a higher factor loading of fruits in our study. Metaanalyses of previous studies have shown that fruit intake decreases the risk of type 2 diabetes ${ }^{(32,33)}$. Fruit consumption may also contribute to the decrease in elevated HbA1c levels associated with the high-bread and low-rice pattern.

The high-meat and low-fish pattern was not associated with elevated HbA1c levels. Unhealthy/Western patterns, characterised mainly by high intakes of red meat, processed foods, high-fat dairy and refined grains, have been associated with an increased risk of developing type 2 diabetes in Western studies ${ }^{(27,34,35)}$. Red and processed 
Dietary patterns and HbA1c

Table 3 Nutrient intakes according to factor score quartiles for the three dietary patterns found among Japanese adults ( $n$ 9550) aged $\geq 40$ years, 2012 National Health and Nutrition Survey

\begin{tabular}{|c|c|c|c|c|c|c|c|c|c|c|c|c|}
\hline & \multicolumn{4}{|c|}{ High-bread and low-rice } & \multicolumn{4}{|c|}{ High-meat and low-fish } & \multicolumn{4}{|c|}{ Vegetable } \\
\hline & \multicolumn{2}{|c|}{ Quartile 1 (low) } & \multicolumn{2}{|c|}{ Quartile 4 (high)* } & \multicolumn{2}{|c|}{ Quartile 1 (low) } & \multicolumn{2}{|c|}{ Quartile 4 (high)* } & \multicolumn{2}{|c|}{ Quartile 1 (low) } & \multicolumn{2}{|c|}{ Quartile 4 (high)* } \\
\hline & Mean & SD & Mean & SD & Mean & SD & Mean & SD & Mean & SD & Mean & SD \\
\hline Total energy (kJ/d) & 8401 & 2272 & 8318 & 1975 & 8343 & 2092 & 8259 & 2180 & 8351 & 2293 & 8272 & 2025 \\
\hline Total energy (kcal/d) & 2008 & 543 & 1988 & 472 & 1994 & 500 & 1974 & 521 & 1996 & 548 & 1977 & 484 \\
\hline Protein (\% energy) & $14 \cdot 2$ & 3.0 & $15 \cdot 1$ & $2 \cdot 8$ & $15 \cdot 2$ & 3.2 & $14 \cdot 6$ & $2 \cdot 8$ & $13 \cdot 9$ & 3.0 & $15 \cdot 7$ & $2 \cdot 9$ \\
\hline Total fat (\% energy) & 23.3 & $7 \cdot 4$ & $25 \cdot 5$ & $6 \cdot 6$ & 19.6 & $6 \cdot 1$ & $29 \cdot 1$ & $6 \cdot 6$ & $23 \cdot 2$ & $7 \cdot 3$ & $25 \cdot 0$ & $7 \cdot 0$ \\
\hline $\begin{array}{l}\text { Carbohydrate } \\
\text { (\% energy) }\end{array}$ & $56 \cdot 0$ & $9 \cdot 7$ & $58 \cdot 1$ & 8.0 & $61 \cdot 9$ & 8.4 & $52 \cdot 3$ & $8 \cdot 0$ & $56 \cdot 5$ & 9.5 & $57 \cdot 7$ & $8 \cdot 6$ \\
\hline $\mathrm{Na}(\mathrm{mg})$ & 4263 & 1708 & 4365 & 1596 & 4588 & 1721 & 4163 & 1565 & 4046 & 1592 & 4675 & 1719 \\
\hline $\mathrm{K}(\mathrm{mg})$ & 2171 & 779 & 2963 & 987 & 2815 & 1041 & 2346 & 825 & 2029 & 735 & 3208 & 954 \\
\hline $\mathrm{Ca}(\mathrm{mg})$ & 417 & 199 & 691 & 269 & 588 & 283 & 494 & 231 & 439 & 220 & 668 & 269 \\
\hline $\mathrm{Mg}(\mathrm{mg})$ & 245 & 84 & 302 & 97 & 298 & 102 & 251 & 82 & 236 & 81 & 319 & 98 \\
\hline$P(\mathrm{mg})$ & 966 & 312 & 1138 & 331 & 1110 & 346 & 989 & 303 & 964 & 323 & 1148 & 326 \\
\hline $\mathrm{Fe}(\mathrm{mg})$ & 7.93 & 2.98 & 8.98 & $3 \cdot 20$ & 9.29 & 3.39 & $7 \cdot 69$ & $2 \cdot 72$ & 7.03 & 2.52 & $10 \cdot 1$ & $3 \cdot 16$ \\
\hline $\mathrm{Zn}(\mathrm{mg})$ & 8.66 & $2 \cdot 71$ & $8 \cdot 16$ & $2 \cdot 52$ & 8.48 & 2.50 & 8.27 & $2 \cdot 87$ & $7 \cdot 66$ & $2 \cdot 63$ & 9.07 & 2.57 \\
\hline $\mathrm{Cu}(\mathrm{mg})$ & 1.26 & 0.52 & 1.28 & 0.46 & 1.43 & 0.57 & $1 \cdot 11$ & 0.38 & $1 \cdot 12$ & 0.40 & 1.42 & 0.41 \\
\hline Vitamin A ( $\mu \mathrm{g} R E$ ) & 486 & 768 & 661 & 563 & 609 & 606 & 504 & 606 & 419 & 509 & 725 & 549 \\
\hline Vitamin D $(\mu \mathrm{g})$ & $7 \cdot 61$ & 8.48 & $9 \cdot 39$ & $9 \cdot 39$ & $12 \cdot 2$ & $10 \cdot 65$ & $5 \cdot 28$ & $6 \cdot 48$ & $8 \cdot 72$ & 9.50 & 8.68 & 8.59 \\
\hline Vitamin E (mg) & $6 \cdot 13$ & $3 \cdot 12$ & 8.32 & 3.79 & $7 \cdot 16$ & 3.81 & $7 \cdot 32$ & 3.46 & 6.45 & 3.33 & 8.29 & 3.90 \\
\hline Vitamin $\mathrm{K}(\mu \mathrm{g})$ & 257 & 186 & 281 & 204 & 290 & 211 & 242 & 169 & 173 & 136 & 379 & 218 \\
\hline Thiamin (mg) & 0.89 & 0.75 & 0.98 & 0.61 & 0.91 & 0.82 & 0.98 & 0.60 & 0.83 & 0.83 & 1.08 & 0.59 \\
\hline Riboflavin (mg) & $1 \cdot 14$ & 0.73 & 1.42 & 0.65 & 1.38 & 0.78 & $1 \cdot 18$ & 0.62 & $1 \cdot 16$ & 0.76 & 1.41 & 0.63 \\
\hline Vitamin $B_{6}(\mathrm{mg})$ & 1.25 & 0.91 & 1.40 & 0.83 & 1.45 & 0.93 & 1.23 & 0.81 & $1 \cdot 13$ & 0.87 & 1.56 & 0.87 \\
\hline Vitamin $B_{12}(\mu \mathrm{g})$ & $6 \cdot 49$ & 7.75 & $7 \cdot 70$ & 7.49 & $9 \cdot 80$ & $9 \cdot 35$ & 4.73 & $5 \cdot 21$ & $7 \cdot 66$ & 7.84 & 6.39 & $6 \cdot 30$ \\
\hline Folate $(\mu \mathrm{g})$ & 300 & 158 & 374 & 154 & 378 & 172 & 296 & 130 & 248 & 116 & 436 & 142 \\
\hline Vitamin C (mg) & 85 & 57 & 160 & 106 & 143 & 100 & 100 & 72 & 75 & 57 & 171 & 101 \\
\hline SFA (\% energy) & 5.64 & $2 \cdot 17$ & $7 \cdot 27$ & $2 \cdot 54$ & 4.96 & 1.99 & $7 \cdot 74$ & 2.47 & $6 \cdot 23$ & $2 \cdot 64$ & $6 \cdot 40$ & $2 \cdot 33$ \\
\hline Dietary fibre (g) & $14 \cdot 1$ & $6 \cdot 0$ & $19 \cdot 2$ & 7.5 & $17 \cdot 7$ & 7.9 & $15 \cdot 8$ & $6 \cdot 4$ & 11.9 & 4.7 & 22.5 & $7 \cdot 1$ \\
\hline n-3 PÚFA (g) & 1.05 & 0.60 & 2.48 & 1.62 & 1.28 & 0.73 & 2.08 & 1.27 & 2.43 & 1.74 & 2.39 & 1.43 \\
\hline n-6 PUFA (g) & 4.46 & 1.73 & $9 \cdot 38$ & 4.44 & 3.52 & 1.48 & $11 \cdot 2$ & 4.86 & $8 \cdot 71$ & 4.42 & $10 \cdot 3$ & 4.76 \\
\hline
\end{tabular}

$R E$, retinol equivalent.

${ }^{\star} P_{\text {trend }}$ used in the general linear model were all $<0.001$.

meat intake among Japanese in the NHNS (corrected mean: $48.7 \mathrm{~g} / \mathrm{d}$ for men and $36.8 \mathrm{~g} / \mathrm{d}$ for women (red meat); $12.0 \mathrm{~g} / \mathrm{d}$ for men and $10.0 \mathrm{~g} / \mathrm{d}$ for women (processed meat)) is considerably lower than that of Western populations, such as the US population, whose mean value is $87.6 \mathrm{~g} / \mathrm{d}$ for men and $52.8 \mathrm{~g} / \mathrm{d}$ for women (red meat), and $29.0 \mathrm{~g} / \mathrm{d}$ for men and $17.7 \mathrm{~g} / \mathrm{d}$ for women (processed meat) ${ }^{(36)}$. One prospective study in Japan indicated no association between the Westernised pattern, characterised by higher intakes of red and processed meat, and type 2 diabetes risk $^{(17)}$. Therefore, differences in intake quantities could explain the disparate results compared with previous Western studies.

The present study has some limitations. First, an association derived from a cross-sectional study could reverse the causal association between dietary patterns and HbA1c levels. Participants with HbA1c levels of $6.5 \%$ or above may have changed their previous dietary pattern by dietary instruction. Dietary patterns of household members with diabetes risk may influence the dietary patterns of other household members. However, we excluded participants with a diagnosis of diabetes and participants undergoing treatment for diabetes mellitus using either insulin or oral drugs from our analysis. Second, we evaluated dietary patterns using factor analysis from dietary records of households with proportional distribution within the house. The proportion of participants to which more than one per household belongs was $27 \%$ of the total. Reliance on household representatives to record dietary intakes in the survey may have resulted in misreporting of various foods, since Japanese working-age men typically eat out for lunch during the week. A previous study investigated the validity of determining consumption by individual family members through household-based and individual-based food weighing methods, and showed that total energy and macronutrient consumption of individual participants showed a high level of agreement among the household-based and individual-based food weighing methods ${ }^{(37)}$. Therefore, dietary records from households with proportional distribution is a valid method to estimate individual intake in the NHNS, which is a large-scale survey. Third, dietary records may not reflect average individual dietary habits, because this survey used dietary records from a single weekday. Also, individual habitual dietary intakes naturally vary from weekdays to weekends. Thus, estimated dietary intake values may be underestimated or overestimated, although this survey was able to assess the habitual dietary intake of a population. Finally, although trained interviewers explained the method of generating 


\section{NSublic Health Nutrition}

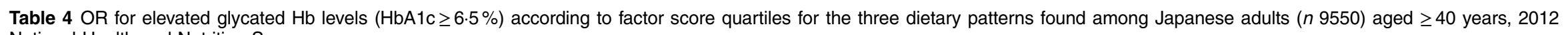
National Health and Nutrition Survey

\begin{tabular}{|c|c|c|c|c|c|c|c|c|c|}
\hline & \multicolumn{8}{|c|}{ Quartile of dietary patterns } & \multirow[b]{3}{*}{$P_{\text {trend }}$} \\
\hline & \multicolumn{2}{|c|}{$\begin{array}{l}\text { Quartile } 1 \\
(n 2388)\end{array}$} & \multicolumn{2}{|c|}{$\begin{array}{c}\text { Quartile } 2 \\
\text { (n 2387) }\end{array}$} & \multicolumn{2}{|c|}{$\begin{array}{l}\text { Quartile } 3 \\
\text { (n 2387) }\end{array}$} & \multicolumn{2}{|c|}{$\begin{array}{c}\text { Quartile } 4 \\
(n 2388)\end{array}$} & \\
\hline & OR & $95 \% \mathrm{Cl}$ & OR & $95 \% \mathrm{Cl}$ & OR & $95 \% \mathrm{Cl}$ & OR & $95 \% \mathrm{Cl}$ & \\
\hline \multicolumn{10}{|l|}{ High-bread and low-rice } \\
\hline No. of cases & \multicolumn{2}{|c|}{91} & \multicolumn{2}{|c|}{92} & \multicolumn{2}{|c|}{59} & \multicolumn{2}{|c|}{67} & \\
\hline Sex- and age-adjusted & 1.00 & Ref. & 1.01 & $0.75,1.37$ & 0.64 & $0.45,0.89$ & 0.73 & $0.52,1.01$ & 0.008 \\
\hline Multivariate ${ }^{*}$ & 1.00 & Ref. & 1.06 & $0.78,1.44$ & 0.67 & $0.48,0.95$ & 0.81 & $0.58,1.14$ & 0.047 \\
\hline \multicolumn{10}{|l|}{ High-meat and low-fish } \\
\hline No. of cases & \multicolumn{2}{|c|}{91} & \multicolumn{2}{|c|}{81} & \multicolumn{2}{|c|}{73} & \multicolumn{2}{|c|}{64} & \\
\hline Sex- and aqe-adjusted & 1.00 & Ref. & 1.03 & $0.76,1.41$ & 1.00 & $0.73,1.38$ & 0.99 & $0.70,1.39$ & 0.904 \\
\hline Multivariate ${ }^{\star}$ & 1.00 & Ref. & 1.05 & $0.77,1.44$ & 1.04 & $0.75,1.44$ & 0.99 & $0.70,1.40$ & 0.972 \\
\hline \multicolumn{10}{|l|}{$\begin{array}{l}\text { Vegetable } \\
\text { Veta }\end{array}$} \\
\hline No. of cases & \multicolumn{2}{|c|}{91} & \multicolumn{2}{|c|}{86} & \multicolumn{2}{|c|}{65} & \multicolumn{2}{|c|}{67} & \\
\hline Sex- and age-adjusted & 1.00 & Ref. & 0.93 & $0.69,1.27$ & 0.68 & $0.49,0.95$ & 0.68 & $0.49,0.95$ & 0.006 \\
\hline Multivariate $^{\star}$ & 1.00 & Ref. & 0.94 & $0.69,1.28$ & 0.70 & $0.50,0.98$ & 0.68 & $0.49,0.95$ & 0.007 \\
\hline
\end{tabular}

Ref., reference category.

${ }^{\star}$ The logistic model adjusted for sex, age, BMI, smoking status and exercise habit. 
dietary records before the survey and checked for any missing information and errors during household visits, dietary intake may have been under- or over-reported because the NHNS used self-administered dietary records. Despite these limitations, these findings will benefit public health in Japan because we used nationwide data representing Japanese people from all geographic regions.

\section{Conclusion}

In conclusion, the vegetable pattern was associated with decreased prevalence of elevated HbA1c levels. Our findings suggest that the vegetable pattern, characterised by higher consumption of vegetables, mushrooms, soyabeans and soyabean products, may help in preventing elevated HbA1c levels occurring with abnormal glucose tolerance among Japanese individuals. Further prospective studies are required to examine the association between Japanese diets and type 2 diabetes using dietary patterns.

\section{Acknowledgements}

Financial support: This research received no specific grant from any funding agency in the public, commercial or not-for-profit sectors. Conflicts of interest: None. Authorship: E.O. analysed the data and wrote the article. K.T. analysed the data. H.T. implemented the survey. A.T., K.N., S.U., S.T., M.N. and all other authors critically revised the article. Ethics of buman subject participation: The National Health and Nutrition Survey is a survey that is conducted by the Ministry of Health, Labour and Welfare in Japan. Therefore, this study is exempt from Institutional Review Board review because these data are publicly available data in which the participants cannot be identified.

\section{Supplementary material}

To view supplementary material for this article, please visit https://doi.org/10.1017/S1368980019000120

\section{References}

1. World Health Organization (2016) Global report on diabetes. https://apps.who.int/iris/bitstream/handle/10665/204871/ 9789241565257_eng.pdf?sequence $=1$ (accessed February 2018).

2. Mathers CD \& Loncar D (2006) Projections of global mortality and burden of disease from 2002 to 2030. PLOS Med 3, e442.

3. Japanese Ministry of Health, Labour and Welfare (2015) Patient Survey. http://www.mhlw.go.jp/toukei/saikin/hw/ kanja/14/dl/kanja.pdf (accessed February 2018).
4. Ikeda N, Nishi N, Noda H et al. (2017) Trends in prevalence and management of diabetes and related vascular risks in Japanese adults: Japan National Health and Nutrition Surveys 2003-2012. Diabetes Res Clin Pract 127, 115-122.

5. Chiuve SE, Fung TT, Rimm EB et al. (2012) Alternative dietary indices both strongly predict risk of chronic disease. J Nutr 142, 1009-1018.

6. Dominguez LJ, Bes-Rastrollo $\mathrm{M}$, de la Fuente-Arrillaga $\mathrm{C}$ et al. (2013) Similar prediction of total mortality, diabetes incidence and cardiovascular events using relative- and absolute-component Mediterranean diet score: the SUN cohort. Nutr Metab Cardiovasc Dis 23, 451-458.

7. Jacobs S, Harmon BE, Boushey CJ et al. (2015) A prioridefined diet quality indexes and risk of type 2 diabetes: the Multiethnic Cohort. Diabetologia 58, 98-112.

8. Qiao Y, Tinker L, Olendzki BC et al. (2014) Racial/ethnic disparities in association between dietary quality and incident diabetes in postmenopausal women in the United States: the Women's Health Initiative 1993-2005. Ethn Health 19, 328-347.

9. InterAct Consortium; Romaguera D, Guevara $\mathrm{M}$ et al. (2011) Mediterranean diet and type 2 diabetes risk in the European Prospective Investigation into Cancer and Nutrition (EPIC) study: the InterAct project. Diabetes Care 34, 1913-1918.

10. Jannasch F, Kröger J \& Schulze MB (2017) Dietary patterns and type 2 diabetes: a systematic literature review and metaanalysis of prospective studies. J Nutr 147, 1174-1182.

11. McEvoy CT, Cardwell CR, Woodside JV et al. (2014) A posteriori dietary patterns are related to risk of type 2 diabetes: findings from a systematic review and meta-analysis. J Acad Nutr Diet 114, 1759.e4-1775.e4.

12. Alhazmi A, Stojanovski E, McEvoy M et al. (2014) The association between dietary patterns and type 2 diabetes: a systematic review and meta-analysis of cohort studies. J Hum Nutr Diet 27, 251-260.

13. Maghsoudi Z, Ghiasvand R \& Salehi-Abargouei A (2016) Empirically derived dietary patterns and incident type 2 diabetes mellitus: a systematic review and meta-analysis on prospective observational studies. Public Health Nutr 19, 230-241.

14. Katanoda K, Kim HS \& Matsumura Y (2006) New Quantitative Index for Dietary Diversity (QUANTIDD) and its annual changes in the Japanese. Nutrition 22, 283-287.

15. Nanri A, Mizoue T, Yoshida D et al. (2008) Dietary patterns and $\mathrm{A} 1 \mathrm{C}$ in Japanese men and women. Diabetes Care 31, 1568-1573.

16. Mizoue T, Yamaji T, Tabata S et al. (2006) Dietary patterns and glucose tolerance abnormalities in Japanese men. J Nutr 136, 1352-1358.

17. Nanri A, Shimazu T, Takachi R et al. (2013) Dietary patterns and type 2 diabetes in Japanese men and women: the Japan Public Health Center-based Prospective Study. Eur J Clin Nutr 67, 18-24.

18. Ikeda N, Takimoto H, Imai S et al. (2015) Data resource profile: The Japan National Health and Nutrition Survey (NHNS). Int J Epidemiol 44, 1842-1849.

19. Japanese Ministry of Health, Labour and Welfare (2015) Ethical Guidelines for Medical and Health Research Involving Human Subjects. Tokyo: Japanese Ministry of Health, Labour and Welfare.

20. National Institute of Health and Nutrition (2011) Outline of the National Health and Nutrition Survey Japan. Tokyo: National Institute of Health and Nutrition.

21. National Institute of Biomedical Innovation, Health and Nutrition (2012) Outline of the National Health and Nutrition Survey (NHNS) Japan, 2012. Tokyo: National Institute of Biomedical Innovation, Health and Nutrition. 
22. Japan Diabetes Society (2016) Diabetes Treatment Guide 2016-2017. Tokyo: Japan Diabetes Society.

23. Japanese Ministry of Health, Labour and Welfare (2015) Dietary Reference Intakes for Japanese. Tokyo: Japanese Ministry of Health, Labour and Welfare.

24. Cattell RB (1965) Factor analysis: an introduction to essentials. II. The role of factor analysis in research. Biometrics 21, 405-435.

25. Morimoto A, Ohno Y, Tatsumi Y et al. (2012) Effects of healthy dietary pattern and other lifestyle factors on incidence of diabetes in a rural Japanese population. Asia Pac J Clin Nutr 21, 601-608.

26. Montonen J, Knekt P, Harkanen T et al. (2005) Dietary patterns and the incidence of type 2 diabetes. Am J Epidemiol 161, 219-227.

27. Erber E, Hopping BN, Grandinetti A et al. (2010) Dietary patterns and risk for diabetes: the Multiethnic Cohort. Diabetes Care 33, 532-538.

28. Schulze MB, Schulz M, Heidemann C et al. (2007) Fiber and magnesium intake and incidence of type 2 diabetes: a prospective study and meta-analysis. Arch Intern Med 167, 956-965.

29. Hu EA, Pan A, Malik V et al. (2012) White rice consumption and risk of type 2 diabetes: meta-analysis and systematic review. BMJ 344, e1454.
30. Foster-Powell K, Holt SH \& Brand-Miller JC (2002) International table of glycemic index and glycemic load values: 2002. Am J Clin Nutr 76, 5-56.

31. Slavin JL, Martini MC, Jacobs DR Jr et al. (1999) Plausible mechanisms for the protectiveness of whole grains. $A m \mathrm{~J}$ Clin Nutr 70, 3 Suppl., 459S-463S.

32. Li M, Fan Y, Zhang X et al. (2014) Fruit and vegetable intake and risk of type 2 diabetes mellitus: meta-analysis of prospective cohort studies. BMJ Open 4, e005497.

33. Wang PY, Fang JC, Gao ZH et al. (2016) Higher intake of fruits, vegetables or their fiber reduces the risk of type 2 diabetes: a meta-analysis. J Diabetes Investig 7, 56-69.

34. Fung TT, Schulze M, Manson JE et al. (2004) Dietary patterns, meat intake, and the risk of type 2 diabetes in women. Arch Intern Med 164, 2235-2240.

35. van Dam RM, Rimm EB, Willett WC et al. (2002) Dietary patterns and risk for type 2 diabetes mellitus in US men. Ann Intern Med 136, 201-209.

36. Daniel CR, Cross AJ, Koebnick C et al. (2011) Trends in meat consumption in the USA. Public Health Nutr 14, $575-583$

37. Iwaoka F, Yoshiike N, Date C et al. (2001) A validation study on a method to estimate nutrient intake by family members through a household-based food-weighing survey. J Nutr Sci Vitaminol (Tokyo) 47, 222-227. 